(2) Open Access Full Text Article

ORIGINAL RESEARCH

\title{
Airway Deposition of Extrafine Inhaled Triple Therapy in Patients with COPD: A Model Approach Based on Functional Respiratory Imaging Computer Simulations
}

This article was published in the following Dove Press journal:

International Journal of Chronic Obstructive Pulmonary Disease

\author{
Omar S Usmani (1D) \\ Nicola Scichilone $\mathbb{D}^{2}$ \\ Benjamin Mignot ${ }^{3}$ \\ Dennis Belmans ${ }^{3}$ \\ Cedric Van Holsbeke $\mathbb{D}^{3}$ \\ Jan De Backer ${ }^{3}$ \\ Roberta De Maria ${ }^{4}$ \\ Erika Cuoghi ${ }^{4}$ \\ Eva Topole ${ }^{4}$ \\ George Georges (iD)
}

'Airway Disease Section, National Heart and Lung Institute, Imperial College, London, UK; ${ }^{2}$ PROMISE Department of Medicine, University of Palermo, Palermo, Italy; ${ }^{3}$ FLUIDDA, Kontich, Belgium; ${ }^{4}$ Chiesi Farmaceutici, SpA, Parma, Italy
Correspondence: George Georges Chiesi USA Inc., 175 Regency Woods

Place, Ste. 600, Cary, NC 27518, USA

$\mathrm{Tel}+$ I (919) 6786611 × 1536

Email george.georges@chiesi.com
Introduction: There is a clear correlation between small airways dysfunction and poor clinical outcomes in patients with chronic obstructive pulmonary disease (COPD), and it is therefore important that inhalation therapy (both bronchodilator and anti-inflammatory) can deposit in the small airways. Two single-inhaler triple therapy (SITT) combinations are currently approved for the maintenance treatment of COPD: extrafine formulation beclomethasone dipropionate/formoterol fumarate/glycopyrronium bromide (BDP/FF/GB), and nonextrafine formulation fluticasone furoate/vilanterol/umeclidinium (FluF/VI/UMEC). This study evaluated the lung deposition of the inhaled corticosteroid (ICS), long-acting $\beta_{2}$-agonist (LABA), and long-acting muscarinic antagonist (LAMA) components of these two SITTs.

Materials and Methods: Lung deposition was estimated in-silico using functional respiratory imaging, a validated technique that uses aerosol delivery performance profiles, patients' high-resolution computed tomography (HRCT) lung scans, and patient-derived inhalation profiles to simulate aerosol lung deposition.

Results: HRCT scan data from 20 patients with COPD were included in these analyses, who had post-bronchodilator forced expiratory volume in 1 second $\left(\mathrm{FEV}_{1}\right)$ ranging from $19.3 \%$ to $66.0 \%$ predicted. For intrathoracic deposition (as a percentage of the emitted dose), deposition of the ICS component was higher from BDP/FF/GB than FluF/VI/UMEC; the two triple therapies had similar performance for both the LABA component and the LAMA component. Peripheral deposition of all three components was higher with BDP/FF/GB than FluF/ VI/UMEC. Furthermore, the ratios of central to peripheral deposition for all three components of $\mathrm{BDP} / \mathrm{FF} / \mathrm{GB}$ were $<1$, indicating greater peripheral than central deposition $(0.48$ $\pm 0.13,0.48 \pm 0.13$ and $0.49 \pm 0.13$ for BDP, FF and GB, respectively; $1.96 \pm 0.84,0.97 \pm 0.34$ and $1.20 \pm 0.48$ for FluF, VI and UMEC, respectively).

Conclusions: Peripheral (small airways) deposition of all three components (ICS, LABA, and LAMA) was higher from BDP/FF/GB than from FluF/VI/UMEC, based on profiles from patients with moderate to very severe COPD. This is consistent with the extrafine formulation of $\mathrm{BDP} / \mathrm{FF} / \mathrm{GB}$.

Keywords: tomography, X-ray computed, metered dose inhalers, dry powder inhalers, inhaled corticosteroid, long-acting beta 2 agonist, long-acting muscarinic antagonist

\section{Introduction}

The small (or peripheral) airways, defined as those with a diameter $<2 \mathrm{~mm}$, are the major site of airflow obstruction in all severities of COPD, ${ }^{1,2}$ with a loss in terminal 
bronchioles and a decrease in alveolar surface area even in patients with mild airflow obstruction. ${ }^{2}$ However, small airways dysfunction (SAD) cannot be detected through standard spirometry, and so may go unnoticed (the socalled "quiet zone"). This is important, as there is a clear correlation between the presence of SAD and increased decline in forced expiratory volume in 1 second $\left(\mathrm{FEV}_{1}\right)$ in patients with COPD. ${ }^{4}$ Further, SAD can be a precursor to the development of emphysema, such that treatments targeting the small airways could potentially reduce emphysema progression. ${ }^{1}$ In addition, increased gas trapping (which is used as a surrogate of SAD) correlates with a number of clinical outcomes in patients with COPD, including decreased six-minute walking distance, increased exacerbation frequency, and worse health status and dyspnea. ${ }^{5}$ Furthermore, small airways resistance (another marker of SAD) correlates with worsening health status in COPD. ${ }^{6}$ Therefore, the ability of a molecule to deposit in the small airways is an important aspect of therapy selection (both bronchodilator and anti-inflammatory) for patients with COPD. ${ }^{7,8}$

The most important determinant of inhaled drug lung delivery is particle size. ${ }^{9}$ Extrafine particles (mass median aerodynamic diameter, MMAD $<2 \mu \mathrm{m}^{10}$ ) in aerosolized medicines are more able to consistently reach small airways than non-extrafine particles, ${ }^{11-13}$ with resulting enhanced drug delivery to these areas, improved overall lung deposition, and lower deposition in the oropharynx. ${ }^{14}$ In turn, lower oropharyngeal deposition decreases the potential for local side effects and systemic absorption. ${ }^{8}$

For patients with COPD who either experience exacerbations despite a long-acting $\beta_{2}$-agonist (LABA) plus a long-acting muscarinic antagonist (LAMA) or experience symptoms or exacerbations despite an inhaled corticosteroid (ICS) plus a LABA, inhaled triple therapy with a triple combination of an ICS, a LABA and a LAMA is recommended. ${ }^{15}$ Two single-inhaler triple ICS/LABA/ LAMA combinations are currently approved for the maintenance treatment of COPD in several countries around the world. One consists of extrafine formulation beclomethasone dipropionate/formoterol fumarate/glycopyrronium bromide (BDP/FF/GB) delivered via pressurized metered dose inhaler (pMDI). The other consists of non-extrafine formulation fluticasone furoate/vilanterol/umeclidinium (FluF/VI/UMEC) delivered via dry powder inhaler (DPI).

The current study's aim was to evaluate the lung deposition of these two single inhaler triple therapies. Evaluations were performed using functional respiratory imaging (FRI), which is a validated computational fluid dynamics (CFD)-based technique that uses aerosol delivery performance profiles, patients' high-resolution computed tomography (HRCT) lung scans, and patientderived inhalation profiles to simulate aerosol lung deposition.

\section{Materials and Methods Study Design}

The FRI technique has been previously described and validated, ${ }^{16}$ and a number of studies have confirmed the good consistency between FRI and scintigraphy. ${ }^{17-29}$ FRI is based on four components: (1) patient-specific 3-D airway geometry modelling; (2) inhaler characteristics; (3) inhalation profile; and (4) CFD simulations to model lung deposition.

No patients were recruited for this study: 3-D geometries of the airways and lungs from patients with COPD who had airflow limitation ranging from moderate to very severe were obtained from the FLUIDDA database, selected to include appropriate age and height ranges. These patientspecific models included the extrathoracic region (comprising the mouth and upper airways) and intrathoracic airways. The analyses presented in this manuscript focus on the intrathoracic airways, which were divided into: the central airways, from the start of the trachea and including all the airways visible on a HRCT scan; and the peripheral (ie, small) airways.

Segmentation and 3D model operations were performed in commercially available validated software packages (Mimics 20.0 and 3-Matic 12.0, Materialise nv, Belgium). Segmentation was automatic, with airways then manually checked and missing branches added. HRCT scans were acquired retrospectively, with informed consent obtained from each patient, and ethical approval granted by the Ethics Committee of the University Hospital in Antwerp, Belgium. HRCT scans were also used to generate models for each of the investigated devices, with the device geometry reverse engineered from the HRCT into a 3D computer-aided design model, and then virtually coupled to patients' airway models.

Intrathoracic deposition of the ICS, LABA and LAMA components were calculated for each inhaler. For both devices, inhalation profiles were constructed based on retrospective patient data from two other sets of patients (different to those from whom the 3-D airways geometries were obtained). For BDP/FF/GB (delivered through a pMDI), 
average flow rates ranged from 16 to $68 \mathrm{~L} / \mathrm{min}$; for FluF/VI/ UMEC (delivered through a DPI), average flows were between 30 and $90 \mathrm{~L} / \mathrm{min}$ (the differences in flows due to differences in the instructions for correct device use). Two inhalation flow profiles were randomly assigned to each patient model, with every patient model assigned one low flow profile (mean $44 \mathrm{~L} / \mathrm{min}$ [range 35-61 L/min]) and one high flow profile (77 [59-94] L/min). Flows were not ageadjusted, and it was assumed that the inhalers were used correctly with no inhalation errors. All particles that are inhaled were assumed to deposit, with no-slip conditions chosen for the airway walls, ie, particles are trapped when they hit the wall. In addition, particles not deposited in either the extrathoracic or central airways were considered to be deposited in the peripheral airways.

\section{Statistical Methods}

All statistical analyses were conducted using $\mathrm{R}$ version 3.2.5 or higher. To investigate statistical equivalence for the deposition patterns, a two-one-sided $t$-test, with equivalence bounds set to $[0.8,1.25]$, was used to assess paired differences per lung region. According to the US Food and Drug Administration Guidance for Industry on Statistical Approaches to Establishing Bioequivalence, the calculated confidence interval of the ratio Test over Reference should fall within the bioequivalence limit of $[0.8,1.25]^{30}$

\section{Results}

\section{Participants}

HRCT scan data from 20 patients with COPD were included in these analyses (Table 1).

Table I Characteristics of Patients Providing HRCT Scan Data

\begin{tabular}{|l|l|}
\hline Parameter & Patients (N=20) \\
\hline Male, n (\%) & $15(75.0)$ \\
Age, years & $64.0 \pm 7.68(44-77)$ \\
Height, cm & $168.9 \pm 8.40(158-188)$ \\
Smoking history, pack-years & $51.3 \pm 29.5(25-110)$ \\
Post-bronchodilator FEV , predicted & $42.3 \pm 14.8(19.3-66.0)$ \\
$50-80 \%, n$ (\%) & $7(35.0)$ \\
$30-50 \%, n$ (\%) & $8(40.0)$ \\
$<30 \%, n$ (\%) & $5(25.0)$ \\
Post-bronchodilator FEV , to FVC ratio & $0.41 \pm 0.14(0.17-0.62)$ \\
\hline
\end{tabular}

Note: Data are mean $\pm S D$ (range) unless specified otherwise. Abbreviations: $\mathrm{FEV}_{1}$, forced expiratory volume in I sec; FVC, forced vital capacity.

\section{Outcomes}

For total intrathoracic drug deposition (ie, central plus peripheral) expressed as a percentage of the emitted dose, deposition of the ICS component was higher from $\mathrm{BDP} / \mathrm{FF} / \mathrm{GB}(35.9 \pm 6.7 \%)$ than FluF/VI/UMEC (23.3 $\pm 4.6 \%$ ), whereas the two triple therapies had similar performance for the LABA component $(36.7 \pm 6.8 \%$ and 34.8 $\pm 4.5 \%)$ and for the LAMA component ( $35.5 \pm 6.5$ and 35.0 $\pm 5.3 \%$; Figure 1). However, peripheral drug deposition of all three components was higher with $\mathrm{BDP} / \mathrm{FF} / \mathrm{GB}$ than with FluF/VI/UMEC (ICS: $24.5 \pm 5.1$ and 8.6 \pm 3.0 ; LABA: 25.0 \pm 5.3 and 18.2 \pm 3.9 ; LAMA: $24.1 \pm 5.1$ and 16.8 \pm 4.9 ; Figure 2). These results were supported by the analysis of statistical equivalence, in which the intrathoracic and peripheral depositions of the ICS component of BDP/FF/GB (ie, BDP) were both significantly higher than that of the ICS component of FluF/VI/UMEC (Figure 3). For the LABA component, whereas intrathoracic deposition met the definition of equivalence, the upper confidence interval of peripheral deposition difference exceeded 1.25 and the confidence interval did not include 1 , indicating greater deposition of this component from BDP/FF/GB. Similarly, for the LAMA component, intrathoracic deposition met the definition of equivalence, but the upper confidence interval of peripheral deposition difference exceeded 1.25 and the confidence interval did not include 1, indicating greater deposition of this component from BDP/FF/GB. Furthermore, the ratio of central to peripheral deposition for all three components of $\mathrm{BDP} / \mathrm{FF} / \mathrm{GB}$ were below 1 , indicating greater deposition in the peripheral airways than the central airways (Table 2). The central-to-peripheral ratio increased slightly with GOLD Grade for some of the molecules (Table 2). This implies that the more severe the airflow limitation is, the more drug deposits in the central region - although the trend to greater peripheral than central deposition of all three components of BDP/ $\mathrm{FF} / \mathrm{GB}$ was unaltered.

One additional advantage of the FRI technique is that it permits a visualization of lung deposition. As can be seen in Figure 4, deposition from BDP/FF/GB was widespread throughout all areas of the lung. In contrast, there was limited peripheral deposition from FluF/VI/UMEC.

\section{Discussion}

These analyses, using computer simulations, demonstrated that the extrafine formulation of $\mathrm{BDP} / \mathrm{FF} / \mathrm{GB}$ provided greater peripheral (small airways) than central deposition. 


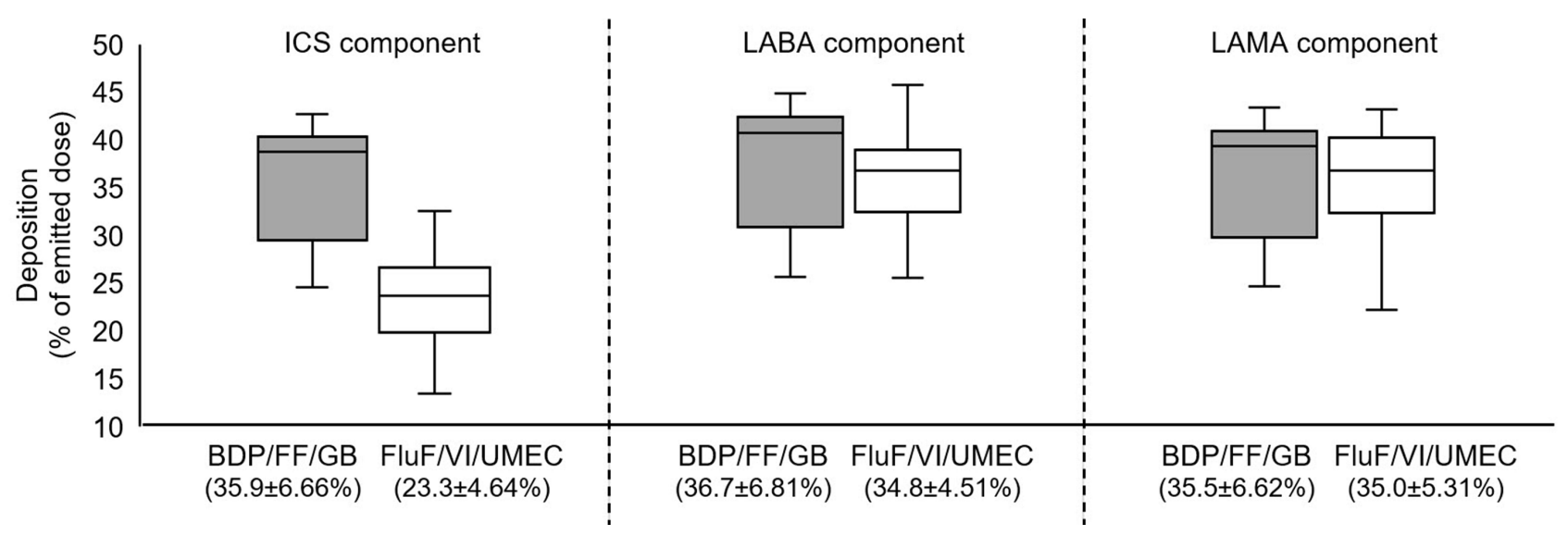

Figure I Intrathoracic deposition as percentage of delivered dose for BDP/FF/GB and FluF/VI/UMEC. Data in brackets on the $\mathrm{x}$-axis are mean \pm standard deviation. The extremes of the box represent the quartiles, the black line gives the median, and the whiskers indicate the range.

Abbreviations: BDP/FF/GB, beclomethasone dipropionate/formoterol fumarate/glycopyrronium bromide; FluF/VI/UMEC, fluticasone furoate/vilanterol/umeclidinium; ICS, inhaled corticosteroid; LABA, long-acting $\beta_{2}$-agonist; LAMA, long-acting muscarinic antagonist.

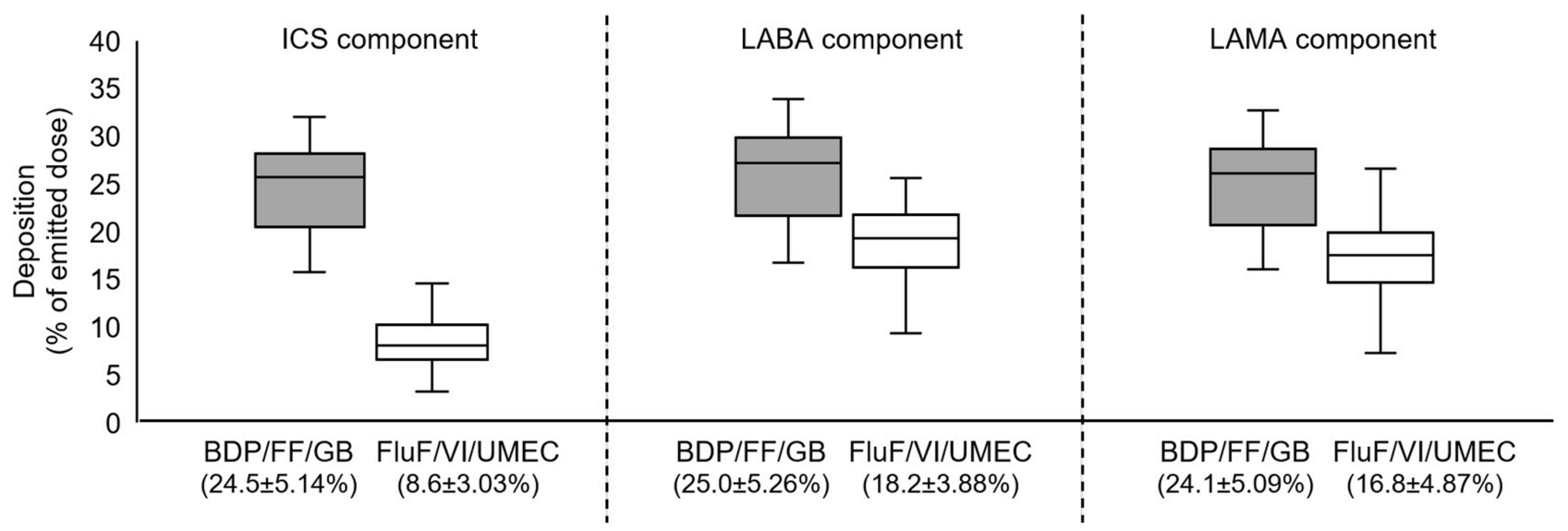

Figure 2 Peripheral airway deposition of delivered dose for BDP/FF/GB and FluF/VI/UMEC. Data in brackets on the $x$-axis are mean \pm standard deviation. The extremes of the box represent the quartiles, the black line gives the median, and the whiskers indicate the range.

Abbreviations: BDP/FF/GB, beclomethasone dipropionate/formoterol fumarate/glycopyrronium bromide; FluF/VI/UMEC, fluticasone furoate/vilanterol/umeclidinium; ICS, inhaled corticosteroid; LABA, long-acting $\beta_{2}$-agonist; LAMA, long-acting muscarinic antagonist.

In addition, the relative deposition patterns are interesting. Overall intrathoracic deposition of the LABA and LAMA components were similar for $\mathrm{BDP} / \mathrm{FF} / \mathrm{GB}$ and FluF/VI/ UMEC. In contrast, a significantly higher proportion of the ICS component was deposited in the intrathoracic region for $\mathrm{BDP} / \mathrm{FF} / \mathrm{GB}$ than was the case for FluF/VI/ UMEC. This could have potential tolerability benefits, in that it suggests lower extrathoracic deposition of the ICS component of $\mathrm{BDP} / \mathrm{FF} / \mathrm{GB}$ - ie, lower deposition in the mouth and upper airways, typically associated with the local adverse effects of ICS preparations, including oral candidiasis and hoarse voice. ${ }^{15}$ This would require further verification in real-world settings or in comparative randomized controlled trials. Importantly, peripheral distribution of all three components of BDP/FF/GB was higher than that of the three components of FluF/VI/UMEC (with consistent deposition for all three components), with the ratio of central to peripheral deposition clearly indicating greater preferential deposition to the small airways of all three components of BDP/FF/GB - especially for the ICS component. This higher peripheral deposition has potential clinical advantages, not only as this is the major site of airflow obstruction in COPD, ${ }^{1,2}$ but given the surface area of the peripheral airways is greater than that of the central airways. ${ }^{9}$ One potential explanation for this deposition pattern is the extrafine formulation of $\mathrm{BDP} / \mathrm{FF} / \mathrm{GB}$, given that other studies have shown the ability of such particles to consistently reach, and deposit in, the small airways. ${ }^{11,14}$ In contrast, the deposition pattern of the three components of FluF/VI/UMEC varied, with almost equal central and 


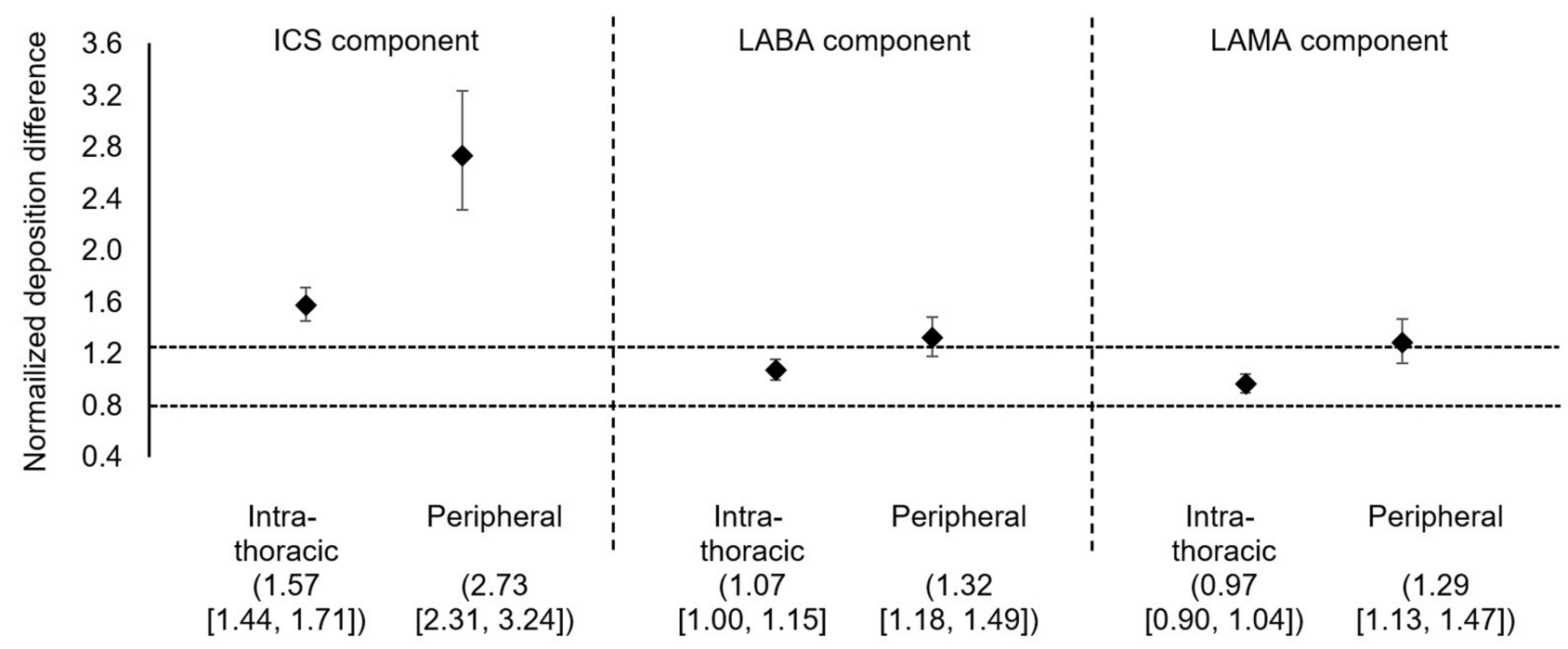

Figure 3 Normalized deposition difference for BDP/FF/GB vs FluF/VI/UMEC. Data are mean and 95\% confidence interval. The dashed horizontal lines are bioequivalence limit of $[0.8,1.25] .^{30}$

Abbreviations: BDP/FF/GB, beclomethasone dipropionate/formoterol fumarate/glycopyrronium bromide; FluF/VI/UMEC, fluticasone furoate/vilanterol/umeclidinium; ICS, inhaled corticosteroid; LABA, long-acting $\beta_{2}$-agonist; LAMA, long-acting muscarinic antagonist.

peripheral deposition for the LABA and LAMA components, whereas the ICS component was nearly twice as likely to deposit centrally than peripherally.

The small airways are difficult to assess directly, especially using standard spirometry - with $\mathrm{FEV}_{1}$ not properly reflecting small airways abnormalities. A range of indirect measures have therefore been employed, including gas trapping and impulse oscillometry. ${ }^{31}$ FRI was developed to use standard HRCT equipment together with computer modelling, with no specialized equipment or techniques required, and so could potentially be a useful tool both in clinical trials and daily practice. Furthermore, as we demonstrated in these analyses, FRI permits detailed evaluation of the deposition of the three components of these inhaled triple therapies - with the ability to visualize the lung deposition especially useful, in particular as part of the drug development process. Although other techniques are available to assess lung deposition, such as gamma scintigraphy, in contrast to FRI these require specialized equipment and techniques. Despite these differences, previous studies evaluating the lung deposition of extrafine $\mathrm{BDP} / \mathrm{FF}$ have shown similar results whether deposition is assessed using FRI $(28 \%)^{17}$ or scintigraphy $(31-34 \%) .^{20,21}$

The study does have some limitations. First, inhalation was simulated from different patients than those who

Table 2 Central to Peripheral Airway Deposition Ratios, Overall and by GOLD Grade. Data are Mean \pm Standard Deviation, with Values Below I Indicating Greater Peripheral Than Central Deposition

\begin{tabular}{|c|c|c|c|c|c|c|}
\hline Component & \multicolumn{3}{|c|}{ BDP/FF/GB $(\mathrm{N}=20)$} & \multicolumn{3}{|c|}{ FluF/VI/UMEC $(\mathrm{N}=20)$} \\
\hline ICS & \multicolumn{3}{|l|}{$0.48 \pm 0.13$} & \multicolumn{3}{|l|}{$1.96 \pm 0.84$} \\
\hline LABA & \multicolumn{3}{|l|}{$0.48 \pm 0.13$} & \multicolumn{3}{|l|}{$0.97 \pm 0.34$} \\
\hline \multirow[t]{3}{*}{ LAMA } & \multicolumn{3}{|l|}{$0.49 \pm 0.13$} & \multicolumn{3}{|l|}{$1.20 \pm 0.48$} \\
\hline & \multicolumn{3}{|c|}{ GOLD Grade } & \multicolumn{3}{|c|}{ GOLD Grade } \\
\hline & $2(N=7)$ & $3(\mathbf{N}=8)$ & $4(N=5)$ & $2(N=7)$ & $3(N=8)$ & $4(N=5)$ \\
\hline ICS & 0.45 & 0.49 & 0.51 & 1.75 & 2.06 & 2.09 \\
\hline LABA & 0.45 & 0.49 & 0.51 & 0.86 & 1.05 & 0.99 \\
\hline LAMA & 0.45 & 0.49 & 0.52 & 1.05 & 1.30 & 1.26 \\
\hline
\end{tabular}

Notes: GOLD Grades are: Grade 2, post-bronchodilator forced expiratory volume in I second 50-80\% predicted; Grade 3, 30-50\%; Grade 4, <30\%.

Abbreviations: BDP/FF/GB, beclomethasone dipropionate/formoterol fumarate/glycopyrronium bromide; FluF/VI/UMEC, fluticasone furoate/vilanterol/umeclidinium; ICS, inhaled corticosteroid; LABA, long-acting $\beta_{2}$-agonist; LAMA, long-acting muscarinic antagonist; GOLD, Global Initiative for Chronic Obstructive Lung Disease. 

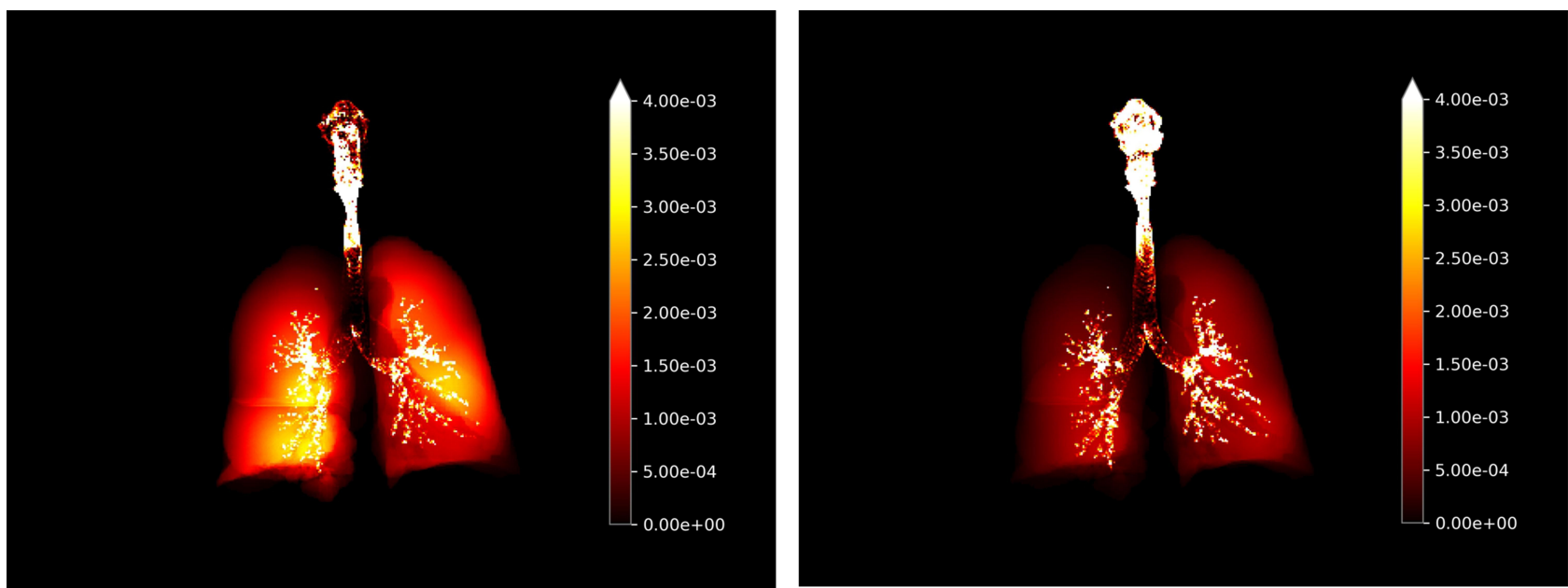

Figure 4 Visualization of deposition in entire respiratory airways of BDP/FF/GB (left hand panel) and FluF/VI/UMEC (right hand panel) (all components, all flow rates). The bright yellow color indicates greater deposition.

Abbreviations: BDP/FF/GB, beclomethasone dipropionate/formoterol fumarate/glycopyrronium bromide; FluF/VI/UMEC, fluticasone furoate/vilanterol/umeclidinium.

provided the HRCT scans - and the inhalation profiles used for the $\mathrm{BDP} / \mathrm{FF} / \mathrm{GB}$ simulations were from different patients than used for the FluF/VI/UMEC simulations. This was for practical reasons, since inhalation profiles were not available for the patients whose scans were used in the study - and the instruction for inhalation through a DPI is not the same as for a pMDI, in particular due to a difference in flows. To get representative results, we selected patients with a broad range of disease severity. Secondly, the clinical impact (in terms of both efficacy and tolerability) of the higher peripheral deposition of triple ICS/LABA/LAMA therapy in COPD has not been evaluated - and indeed there are no head-to-head studies of these two triple therapies. A number of systematic literature reviews and meta-analyses have been published which attempt indirect comparisons of triple therapies in patients with COPD (either single- or multiple-inhaler); in these evaluations the effects of triple therapies seem broadly consistent, but are hindered by differences in study design and the populations recruited. ${ }^{32-34}$ Thirdly, as data were obtained from a database with no patients specifically recruited for the study, data on their disease characteristics are limited to lung function, and we have no information on their medication. Finally, this study involved two different sets of molecules, delivered from two different inhaler types, and so comparisons should be made with care. However, when selecting therapies for COPD, the choice of inhaler device has to be individually tailored, depending on a patient's ability and preference. ${ }^{15,35}$ Indeed, the use of extrafine triple therapy has translated into clinical benefits in randomized controlled trials of patients with COPD. ${ }^{36-39}$ In this respect, the ability of inhaled molecules to target the peripheral airways is an important additional consideration when selecting a therapy.

\section{Conclusions}

Peripheral (small airways) deposition of all three components (ICS, LABA, and LAMA) was higher from BDP/FF/ GB than from FluF/VI/UMEC, using FRI simulations based on profiles from patients with moderate to very severe COPD. This is consistent with the extrafine particle size formulation of $\mathrm{BDP} / \mathrm{FF} / \mathrm{GB}$.

\section{Data Sharing Statement}

Chiesi commits to sharing with qualified scientific and medical researchers, conducting legitimate research, patient-level data, study-level data, the clinical protocol and the full clinical study report of Chiesi Farmaceutici S.p.A.-sponsored interventional clinical trials in patients for medicines and indications approved by the European Medicines Agency and/or the US Food and Drug Administration after 1st January 2015, following the approval of any received research proposal and the signature of a Data Sharing Agreement. Chiesi provides access to clinical trial information consistently with the principle of safeguarding commercially confidential information and patient privacy. Other information on Chiesi's data sharing commitment, access and research request's approval process is available in the Clinical Trial Transparency section of http://www.chiesi.com/en/research-and-development/. 


\section{Ethics Approval and Informed Consent}

Informed consent was obtained from each patient, and ethical approval was granted by the Ethics Committee of the University Hospital in Antwerp, Belgium.

\section{Consent for Publication}

Not applicable.

\section{Acknowledgments}

Writing support was provided by David Young of Young Medical Communications and Consulting Ltd. This support was funded by Chiesi Farmaceutici SpA.

\section{Funding}

This study was funded by Chiesi Farmaceutici SpA. Employees of the sponsor were involved in the interpretation of the study results, and in the development of the manuscript and the decision to submit for publication.

\section{Disclosure}

OSU reports grants and personal fees from AstraZeneca, Boehringer Ingelheim, Chiesi and GlaxoSmithKline, personal fees from Aerocrine, Napp, Mundipharma, Novartis, Sandoz, Takeda, Zentiva, Covis, and Cipla, and grants from Edmond Pharma, all of which are outside the submitted work. NS received honoraria from Astra Zeneca, Chiesi, GSK and Sanofi, and grants for research from Astra Zeneca, Boehringer Ingelheim, GSK and Sanofi. $\mathrm{BM}, \mathrm{DB}, \mathrm{CVH}$ and JDB are employees of FLUIDDA (and JDB is a shareholder of FLUIDDA); FLUIDDA received funding from Chiesi Farmaceutici SpA to conduct the analyses reported in this manuscript. RDM, EC, ET and GG are employees of Chiesi, the sponsor of the study. ET reports personal fees from Novartis, Teva Respiratory, Berlin Chemie, GSK, and Abbott Laboratories, outside the submitted work. The authors report no other conflicts of interest in this work.

\section{References}

1. Higham A, Quinn AM, Cançado JED, Singh D. The pathology of small airways disease in COPD: historical aspects and future directions. Respir Res. 2019;20(1):49. doi:10.1186/s12931-019-1017-y

2. Koo H-K, Vasilescu DM, Booth S, et al. Small airways disease in mild and moderate chronic obstructive pulmonary disease: a cross-sectional study. Lancet Respir Med. 2018;6(8):591-602. doi:10.1016/S22132600(18)30196-6

3. Mead J. The lung's “quiet zone. N Engl J Med. 1970;282(23):13181319. doi:10.1056/NEJM197006042822311
4. Bhatt SP, Soler X, Wang X, et al. Association between functional small airway disease and FEV1 decline in chronic obstructive pulmonary disease. Am J Respir Crit Care Med. 2016;194(2):178-184. doi:10.1164/rccm.201511-2219OC

5. Hersh CP, Washko GR, Estépar RSJ, et al. Paired inspiratory-expiratory chest CT scans to assess for small airways disease in COPD. Respir Res. 2013;14(1):42. doi:10.1186/1465-9921-14-42

6. Crisafulli E, Pisi R, Aiello M, et al. Prevalence of small-airway dysfunction among COPD patients with different GOLD stages and its role in the impact of disease. Respiration. 2017;93(1):32-41. doi: $10.1159 / 000452479$

7. Tzani P, Crisafulli E, Nicolini G, et al. Effects of beclomethasone/ formoterol fixed combination on lung hyperinflation and dyspnea in COPD patients. Int J Chron Obstruct Pulmon Dis. 2011;6:503-509. doi:10.2147/COPD.S23746

8. Usmani OS. Treating the small airways. Respiration. 2012;84 (6):441-453. doi:10.1159/000343629

9. Lipworth B, Manoharan A, Anderson W. Unlocking the quiet zone: the small airway asthma phenotype. Lancet Respir Med. 2014;2 (6):497-506. doi:10.1016/S2213-2600(14)70103-1

10. Hillyer EV, Price DB, Chrystyn H, et al. Harmonizing the nomenclature for therapeutic aerosol particle size: a proposal. $J$ Aerosol Med Pulm Drug Deliv. 2018;31(2):111-113. doi:10.1089/jamp.2017.1396

11. Braido F, Scichilone N, Lavorini F, et al. Manifesto on small airway involvement and management in asthma and chronic obstructive pulmonary disease: an Interasma (Global Asthma Association GAA) and World Allergy Organization (WAO) document endorsed by Allergic Rhinitis and its Impact on Asthma. World Allergy Organ J. 2016;9(1):1-6. doi:10.1186/s40413-016-0123-2

12. Lavorini F, Pedersen S, Usmani OS; on behalf of the Aerosol Drug Management Improvement Team (ADMIT). Dilemmas, confusion, and misconceptions related to small airways directed therapy. Chest. 2017;151(6):1345-1355. doi:10.1016/j.chest.2016.07.035

13. Usmani OS, Barnes PJ. Assessing and treating small airways disease in asthma and chronic obstructive pulmonary disease. Ann Med. 2012;44(2):146-156. doi:10.3109/07853890.2011.585656

14. Usmani OS, Biddiscombe MF, Barnes PJ. Regional lung deposition and bronchodilator response as a function of beta2-agonist particle size. Am J Respir Crit Care Med. 2005;172(12):1497-1504. doi:10.1164/rccm.200410-1414OC

15. Global Initiative for Chronic Obstructive Lung Disease. Global strategy for the diagnosis, management, and prevention of chronic obstructive pulmonary disease; 2020. Available from: https://gold copd.org/gold-reports/. Accessed September 5, 2020.

16. De Backer JW, Vos WG, Vinchurkar SC, et al. Validation of computational fluid dynamics in CT-based airway models with SPECT/CT. Radiology. 2010;257(3):854-862. doi:10.1148/radiol.10100322

17. Usmani $\mathrm{O}$, Vos $\mathrm{W}$, Mignot $\mathrm{B}$, et al. Lung deposition of extrafine inhaled corticosteroid (ICS)-containing fixed combinations drug in COPD patients using Functional Respiratory Imaging (FRI). Eur Respir J. 2018;52(suppl 62):PA1015. doi:10.1183/13993003.congress-2018.PA1015

18. Kappeler D, Sommerer K, Kietzig C, et al. Lung deposition of fluticasone propionate/formoterol administered via a breath-triggered inhaler. Eur Respir J. 2017;50(suppl 62):PA522.

19. Müllinger B, Brand P, Fischer A, et al. Intra-pulmonal deposition of two different tobramycin formulations. J Cyst Fibros. 2005;4(suppl 1):S53(abstract 198).

20. De Backer W, Devolder A, Poli G, et al. Lung deposition of BDP/ formoterol HFA pMDI in healthy volunteers, asthmatic, and COPD patients. J Aerosol Med Pulm Drug Deliv. 2010;23(3):137-148. doi:10.1089/jamp.2009.0772

21. De Maria R, Zagnoni I, Bodria A, et al. Foster ${ }^{\mathbb{B}}$ : a high-efficiency combination metered dose inhaler with consistent particle size distribution at alternative flow rates. Comb Prod Ther. 2014;4(1-2):1-5. doi:10.1007/s13556-013-0006-6 
22. Iwanaga T, Kozuka T, Nakanishi J, et al. Aerosol deposition of inhaled corticosteroids/long-acting $\beta 2$-agonists in the peripheral airways of patients with asthma using functional respiratory imaging, a novel imaging technology. Pulm Ther. 2017;3(1):219-231. doi:10.1007/s41030-017-0036-4

23. Hirst PH, Bacon RE, Pitcairn GR, Silvasti M, Newman SP. A comparison of the lung deposition of budesonide from Easyhaler, Turbuhaler and pMDI plus spacer in asthmatic patients. Respir Med. 2001;95(9):720-727. doi:10.1053/rmed.2001.1107

24. Leach CL, Kuehl PJ, Chand R, McDonald JD. Respiratory tract deposition of HFA-beclomethasone and HFA-fluticasone in asthmatic patients. J Aerosol Med Pulm Drug Deliv. 2016;29(2):127-133. doi:10.1089/jamp.2014.1199

25. Nikander K, Prince I, Coughlin S, Warren S, Taylor G. Mode of breathing-tidal or slow and deep-through the I-neb Adaptive Aerosol Delivery (AAD) system affects lung deposition of (99m)Tc-DTPA. $J$ Aerosol Med Pulm Drug Deliv. 2010;23(Supp11):S37-S43. doi:10.1089/jamp.2009.0786

26. Hull D, Black A, Vos W. Use of computational fluid dynamics (CFD) to model aerosol deposition in the lungs of patients with cystic fibrosis. $J$ Cyst Fibros. 2018;17(suppl 3):S26. doi:10.1016/S1569-1993(18)30199-1

27. Lenney W, Edenborough F, Kho P, Kovarik JM. Lung deposition of inhaled tobramycin with eFlow rapid/LC Plus jet nebuliser in healthy and cystic fibrosis subjects. $J$ Cyst Fibros. 2011;10(1):9-14. doi:10.1016/j.jcf.2010.08.019

28. Fischer A, Stegemann J, Scheuch G, Siekmeier R. Novel devices for individualized controlled inhalation can optimize aerosol therapy in efficacy, patient care and power of clinical trials. Eur J Med Res. 2009;14(Suppl 4):71-77. doi:10.1186/2047-783x-14-s4-71

29. Munro S, Main M, Vos W Matching delivery device to a patient's condition: use of lung deposition modelling to optimise delivery in idiopathic pulmonary fibrosis. In: Drug Delivery to the Lungs Annual Congress; 2017.

30. US Food and Drug Administration. Statistical approaches to establishing bioequivalence; 2001. Available from: https:/www.fda.gov/regula tory-information/search-fda-guidance-documents/statisticalapproaches-establishing-bioequivalence. Accessed September 5, 2020.
31. Bonini M, Usmani OS. The role of the small airways in the pathophysiology of asthma and chronic obstructive pulmonary disease. Ther Adv Respir Dis. 2015;9(6):281-293. doi:10.1177/1753465815588064

32. Langham S, Lewis J, Pooley N, et al. Single-inhaler triple therapy in patients with chronic obstructive pulmonary disease: a systematic review. Respir Res. 2019;20(1):242. doi:10.1186/s12931-019-1213-9

33. Lopez-Campos JL, Carrasco-Hernandez L, Quintana-Gallego E, et al. Triple therapy for COPD: a crude analysis from a systematic review of the evidence. Ther Adv Respir Dis. 2019;13:175346661988552. doi:10.1177/1753466619885522

34. Zheng Y, Zhu J, Liu Y, et al. Triple therapy in the management of chronic obstructive pulmonary disease: systematic review and metaanalysis. BMJ. 2018;363:k4388. doi:10.1136/bmj.k4388

35. Bonini M, Usmani OS. The importance of inhaler devices in the treatment of COPD. COPD Res Pract. 2015;1(1):1-9. doi:10.1186/ s40749-015-0011-0

36. Singh D, Corradi M, Spinola M, et al. Triple therapy in COPD: new evidence with the extrafine fixed combination of beclomethasone dipropionate, formoterol fumarate, and glycopyrronium bromide. Int J COPD. 2017;12:2917-2928. doi:10.2147/COPD.S146822

37. Papi A, Vestbo J, Fabbri L, et al. Extrafine inhaled triple therapy versus dual bronchodilator therapy in chronic obstructive pulmonary disease (TRIBUTE): a double-blind, parallel group, randomised controlled trial. Lancet. 2018;391(10125):1076-1084. doi:10.1016/ S0140-6736(18)30206-X

38. Singh D, Papi A, Corradi M, et al. Single inhaler triple therapy versus inhaled corticosteroid plus long-acting $\beta 2$-agonist therapy for chronic obstructive pulmonary disease (TRILOGY): a double-blind, parallel group, randomised controlled trial. Lancet. 2016;388(10048):963973. doi:10.1016/S0140-6736(16)31354-X

39. Vestbo J, Papi A, Corradi M, et al. Single inhaler extrafine triple therapy versus long-acting muscarinic antagonist therapy for chronic obstructive pulmonary disease (TRINITY): a double-blind, parallel group, randomised controlled trial. Lancet. 2017;389(10082):19191929. doi:10.1016/S0140-6736(17)30188-5

\section{Publish your work in this journal}

The International Journal of COPD is an international, peer-reviewed journal of therapeutics and pharmacology focusing on concise rapid reporting of clinical studies and reviews in COPD. Special focus is given to the pathophysiological processes underlying the disease, intervention programs, patient focused education, and self management protocols. This journal is indexed on PubMed Central, MedLine and CAS. The manuscript management system is completely online and includes a very quick and fair peer-review system, which is all easy to use. Visit http://www.dovepress.com/testimonials.php to read real quotes from published authors. 